Rabaska

Revue d'ethnologie de l'Amérique française

BERTHOld, ÉTIENNe (dir.). Le Patrimoine des communautés

religieuses : empreintes et approches. Québec, Presses de

l’Université Laval, 2018, 301 p. ISBN 978-2-7637-3642-6

\title{
Claudine Papin
}

Volume 17, 2019

URI : https://id.erudit.org/iderudit/1066024ar

DOI : https://doi.org/10.7202/1066024ar

Aller au sommaire du numéro

Éditeur(s)

Société québécoise d'ethnologie

ISSN

1703-7433 (imprimé)

1916-7350 (numérique)

Découvrir la revue

Citer ce compte rendu

Papin, C. (2019). Compte rendu de [BERTHOLD, ÉTIENNE (dir.). Le Patrimoine des communautés religieuses : empreintes et approches. Québec, Presses de

I’Université Laval, 2018, 301 p. ISBN 978-2-7637-3642-6]. Rabaska, 17, 287-289.

https://doi.org/10.7202/1066024ar d'utilisation que vous pouvez consulter en ligne.

https://apropos.erudit.org/fr/usagers/politique-dutilisation/ 


\section{Comptes rendus}

Berthold, Étienne (dir.). Le Patrimoine des communautés religieuses : empreintes et approches. Québec, Presses de l'Université Laval, 2018, 301 p. ISBN 978-2-7637-3642-6.

Cet ouvrage collectif rassemble les communications d'un colloque tenu en juin 2016 au Monastère des Augustines à Québec. Il propose une nouvelle voie pour l'étude du patrimoine des communautés religieuses : le patrimoine social. Outre la mise en perspective de l'ouvrage sous la direction d'Étienne Berthold, onze chercheurs, professeurs ou intervenants y débusquent l'action sociale menée par des communautés religieuses et les processus de patrimonialisation qui s'y rattachent. Berthold, professeur agrégé au département de géographie de l'Université Laval, a conduit plusieurs travaux sur le patrimoine des communautés religieuses et plus particulièrement celles de la ville de Québec. Les collaborateurs qu'il a réunis offrent différents points de vue tant du domaine de l'archivistique, de la muséologie, de l'histoire, de l'ethnologie, de l'anthropologie sociale que celui de la géographie et des études urbaines, culturelles ou touristiques.

D'entrée de jeu, Berthold inscrit sa réflexion dans les profondes transformations que vivent les communautés religieuses catholiques et les multiples préoccupations que cela entraîne dans la société laïque ainsi que l'expansion de la recherche visant le patrimoine. Sujet préoccupant puisqu'on rapporte que quelque 150 communautés religieuses étaient en activité en 2009 et, pour une majorité, en voie de connaître des changements majeurs allant parfois jusqu'à leur disparition. De plus en plus d'études sont consacrées à l'histoire des communautés religieuses afin de caractériser, conserver et mettre en valeur leur héritage matériel et immatériel. Par cet ouvrage, Berthold propose une approche qui ne traite pas en priorité des manifestations architecturales ou des faits ethnologiques caractéristiques du patrimoine des communautés religieuses, mais plutôt de «l'action que mènent les congrégations religieuses à l'échelle sociale, sur les dynamiques qui régissent cette action, ainsi que sur les processus qui l'érigent en "patrimoine social". » Il invite à envisager le fondement des œuvres des 
communautés religieuses en fonction de l'atteinte d'une finalité. Berthold nous rappelle que " plusieurs études abordent la dimension spirituelle et religieuse des œuvres comme le fondement le plus irréductible du patrimoine des communautés religieuses et mettent en relief les dispositifs organisationnels et institutionnels qui encadrent le travail d'interprétation de ce même patrimoine. »

Toutefois, ce livre se distingue en démontrant que le patrimoine des communautés religieuses dépasse l'univers strictement religieux et porte des finalités ayant un impact sur les dynamiques sociales, économiques et politiques d'une société. Fort de l'émergence d'une conception du patrimoine social qu'il contribue rigoureusement à enrichir, Berthold n'hésite pas à poser l'hypothèse que l'héritage des communautés religieuses a laissé des traces qui sont encore agissantes dans nos sociétés contemporaines. De là l'idée d'en examiner les empreintes et ce plus particulièrement dans le domaine de l'éducation, de la santé et du travail social.

L'objectif principal de l'ouvrage est donc d'explorer divers aspects et manifestations du concept de patrimoine social des communautés religieuses. Les premiers scrutent le développement d'institutions et d'organisations d'importance. L'empreinte du patrimoine seigneurial du Séminaire de Québec, des grands domaines de Sillery, propriétés de communautés religieuses et celui des Augustines y sont présentés. Ces trois communications abordent tour à tour comment ces institutions anciennes influencent encore aujourd'hui la question de l'occupation et de l'aménagement du territoire, de l'urbanisme et dans le cas du Monastère des Augustines de l'Hôtel-Dieu de Québec de la réhabilitation d'une propriété conventuelle.

Par la suite, cinq auteurs collaborateurs fouillent l'empreinte majoritairement des communautés religieuses féminines sur le développement de pratiques sociales structurantes. On y aborde la façon dont elles usaient des musées scolaires pour alimenter leurs œuvres et leurs visées éducatives. Ensuite on examine comment la mémoire photographique permet de décoder autrement le quotidien et les pratiques, dans ce cas-ci, des Augustines de Québec. S'ensuit une relecture du patrimoine architectural des Ursulines de Trois-Rivières afin de considérer comment cette communauté interagit avec les collectivités qui l'entourent. Puis, on nous propose un regard sur les empreintes patrimoniales qui marquent les rencontres entre des communautés religieuses et des peuples des Premières Nations au Canada. Pour terminer cette observation du patrimoine social du point de vue de pratiques sociales structurantes, le dernier texte «porte sur les rapports entre la pratique religieuse, le pouvoir politique et la laïcité dans la Russie postsoviétique (1992- ). » 
Les derniers textes de l'ouvrage examinent eux aussi l'empreinte de l'héritage des communautés religieuses, cette fois sous l'angle du développement des communautés locales. On y retrouve une analyse de la participation citoyenne dans des projets de mise en valeur du patrimoine religieux catholique au Québec ; le deuxième texte aborde l'impact de la conservation du patrimoine matériel et immatériel sur les collectivités néerlandaises ; et le dernier traite de la façon dont le tourisme contribue à la mise en valeur du patrimoine matériel et immatériel des communautés religieuses.

L'ouvrage rend bien justice à son sous-titre. Chaque communication ne manque pas de nous faire saisir comment les communautés religieuses actives dans différents secteurs de la vie socioéconomique ont laissé des empreintes reconnaissables encore aujourd'hui et souvent vivantes dans des projets qui les traduisent et les actualisent.

Claudine Papin

Conseillère en patrimoine social Monastère des Augustines

Bourgine, Benoît, Joseph Famerée et Paul Scolas (dir.). En finir avec le Diable? Les enjeux d'une figure du mal. Louvain-la-Neuve, AcademiaL'Harmattan S. A., 2018, 187 p. ISBN 978-2-8061-0358-1.

Son nom s'écrit le plus souvent avec la minuscule quand il s'agit de cerner une puissance maléfique aux contours vagues et à l'action rampante, parfois avec la majuscule quand l'intention est de le doter d'une personnalité propre. Entité insaisissable, il se tapit au milieu de ses multiples dénominations quand il se sait acculé, à l'image de la chanson des métamorphoses dans laquelle l'amant poursuit celle qu'il aime à travers ses avatars successifs. Ceux qui en arrachent avouent qu'ils le tirent par la queue et ne doutent ni de son existence ni de son emprise. Tel apparaît le D/diable au gré de ses innombrables hypostases que la nomenclature de ses identités plurielles vient accréditer : le Diable, Satan, le Tentateur, l'Adversaire, l'Ennemi, l'Antique Serpent, le Mauvais, le Malin, etc. (Elian Cuvillier, p. 21). À ce catalogue déjà bien fourni s'ajoutent les noms que lui donne la tradition orale qui ne cache pas une certaine familiarité avec le triste sire : Jack, Charlie, le Singe de Dieu, le vieux Jérôme.

L'amoncellement des témoignages et des études à son sujet est tel qu'on se demande, perplexe, si on en finira un jour avec lui. C'est précisément la question que se sont posée les participants au XIII colloque Gesché qui lui a été consacré à l'Université catholique de Louvain (UCL): En finir avec le 